\title{
In Vitro Propagation of Resurrection Plant Selaginella pulvinata Using Frond Tips as Explants
}

\author{
Rongpei Yu \\ School of Life Sciences, School of Ecology and Environmental Sciences, \\ Institute of Ecology and Geobotany, Yunnan University, Kunming, Yunnan \\ 650091, China; Flower Research Institute, Yunnan Academy of Agricultural \\ Sciences, National Engineering Research Center for Ornamental \\ Horticulture, Kunming, Yunnan 650205, China; and Yuxi Yunxing Biotech \\ Co., Ltd., Yuxi, Yunnan 653100, China
}

\section{Ying Cheng and Yanfei Pu \\ School of Agriculture, Yunnan University, Kunming, Yunnan 650504, China}

\section{Fan Li}

Flower Research Institute, Yunnan Academy of Agricultural Sciences, National Engineering Research Center for Ornamental Horticulture, Kunming, Yunnan 650205, China; and Yuxi Yunxing Biotech Co., Ltd., Yuxi, Yunnan 653100, China

\section{Shugang Lu}

School of Life Sciences, School of Ecology and Environmental Sciences, Institute of Ecology and Geobotany, Yunnan University, Kunming, Yunnan 650091, China

Additional index words. cytokinin, in vitro propagation, resurrection plants, Selaginella pulvinata

\begin{abstract}
The resurrection plant Selaginella pulvinata (Hook. \& Grev.) Maxim is used as an ornamental and medicinal plant. It is also a good candidate for exploring the desiccation tolerance of resurrection plants. However, there is not an efficient propagation method for $S$. pulvinata. In the present study, we evaluated the establishment of in vitro propagation of $S$. pulvinata using frond tips as explants. The original shoot induction, adventitious shoot proliferation and plantlet growth media, and substrate type of plantlet acclimatization were investigated. The highest induction rate of original shoots $(61.77 \pm 5.17 \%)$ was obtained on half-strength $(\mathbf{1} / \mathbf{2})$ MS medium supplemented with $0.1 \mathrm{mg} \cdot \mathrm{L}^{-1} \mathrm{~N}^{6}$-benzylaminopurine (BAP). The $1 / 2 \mathrm{MS}$ with $1.0 \mathrm{mg} \cdot \mathrm{L}^{-1}$ BAP was the most effective medium for the adventitious shoot proliferation. The quarter-strength (1/ 4) MS containing $0.1 \%(\mathrm{w} / \mathrm{v})$ active charcoal (AC) was optimum for plantlets proliferated from adventitious shoots and plantlet growth. Approximately 98 plantlets could be obtained from one single original shoot via one-time shoot proliferation cultivation and plantlet cultivation. The acclimated plants on a 5:1 (v/v) mixture of peat and perlite had the highest survival rate $(92.13 \pm 1.67 \%)$. The acclimated plants maintained excellent resurrection ability.
\end{abstract}

Selaginella P. Beauv. (Selaginellaceae), an ancient and distinctive group, is the largest genus of seed-free vascular plants, with an

\footnotetext{
Received for publication 3 Nov. 2020. Accepted for publication 11 Dec. 2020

Published online 26 January 2021.

We thank the National Natural Science Foundations of China (grant no. 31860569) and the Science and Technology Talents and Platform Program of Yunnan Province - Rongpei Yu (2021-2026) for financial support.

S.L. is the corresponding author. E-mail: shuganglu@ 163.com.

This is an open access article distributed under the CC BY-NC-ND license (https://creativecommons. org/licenses/by-nc-nd/4.0/).
}

estimated 700 to 800 species that exploit a diverse array of the arctic, temperate, tropical, and semi-arid habitats (Arrigo et al., 2013; Banks, 2009; Jermy, 1986; Singh et al., 2019; Zhou et al., 2016). Some species of Selaginella are resurrection plants, such as S. tamariscina (Wang et al., 2010; $\mathrm{Xu}$ et al., 2018), S. lepidophylla (Pampurova et al., 2014; Rafsanjani et al., 2015; Yobi et al., 2013), S. bryopteris (Deeba et al., 2016), S. arizonica, S. eremophila, and $S$. rupincola of the North American southwestern deserts ( $\mathrm{Yu}$ et al., 2017a). With the remarkable vegetative desiccation tolerance, the resurrection plants are able to survive nearly complete anhydrobiosis $(<10 \%$ relative water content) during prolonged drought events and resume normal growth when water is available (VanBuren et al., 2018). The phenomenon that the dry and visually "dead" plants come alive after rewatering is fascinating to plant biologists and the lay public (Xiao et al., 2015), thus making resurrection plants a special group of ornamental plants. Interestingly, the nuclear genomes of Selaginella are some of the smallest among green plants (Baniaga et al., 2016; Little et al., 2007; Obermayer et al., 2002). Therefore, the resurrection species of Selaginella are good candidates for exploring the mechanisms of desiccation tolerance with genomic-based approaches (VanBuren et al., 2018).

Selaginella pulvinata (Hook. \& Grev.) Maxim, a typical resurrection plant mainly distributed in exposed limestone areas, has varied usefulness in China (Zhang and Zhang, 2004). It is renowned as an ornamental plant because of its magical resurrection ability, and it is an important medicinal plant listed in Chinese Pharmacopoeia (Chinese Pharmacopoeia Committee, 2015). S. pulvinata is used in traditional Chinese medicine for the treatment of traumatic injury and asthma (Cao et al., 2010). Pharmacological investigations revealed its various biological activities, such as anti-cancer (Wang et al., 2016) and anti-inflammatory effects (Huang et al., 2017). Unfortunately, because of its overexploitation, populations of $S$. pulvinata have decreased sharply. Therefore, there is an urgent need to establish the in vitro propagation of $S$. pulvinata to produce high-quality plantlets for horticultural and medicinal use without resorting to harvesting wild populations.

Many fern species have been successfully established in an in vitro propagation system via spores (Barnicoat et al., 2011) and shoot organogenesis from juvenile leaves (Camloha et al., 1994), rhizomes (Winarto and Teixeira da Silva, 2012), callus (Hegde et al., 2006), somatic embryos (Mikuła et al., 2015a, 2015b), and green globular bodies (GGBs) (Amaki and Higuchi, 1991). Among them, the GGB system is regarded as a remarkably efficient method (Higuchi et al., 1987). However, studies of in vitro propagation of fern-ally Selaginella are limited. Park et al. (2020) reported in vitro regeneration of nonresurrection species $S$. martensii by using shoot-tips as explants. Because of the different germination times of megaspores and microspores in resurrection species $S$. eremophila, S. rupincola, and S. arizonica, a twostep in vitro propagation method was used: surface-sterilized megaspores were cultured alone for 3 weeks, followed by the addition of surface-sterilized microspores to the germinated megaspore cultures for co-culture; however, the final fertilization rate was only $\approx 12 \%$ in $S$. eremophila and S. rupincola, and no fertilization was observed in $S$. arizonica (Yu et al., 2017a). Additionally, there are no reports of in vitro vegetative propagation of resurrection species in Selaginella.

We describe an in vitro vegetative propagation protocol for resurrection plant $S$. pulvinata using frond tips as explants. We 
investigated the optimal media for original shoot induction, adventitious shoot proliferation and plantlet growth, and the optimal substrate type for plantlet acclimatization. This new protocol will be beneficial for horticultural and medicinal applications of $S$. pulvinata and will be a critical tool for researching the biology of desiccation tolerance.

\section{Materials and Methods}

Plant material. S. pulvinata plants (plant diameter, $5.0-8.0 \mathrm{~cm}$ ) were collected from exposed limestone in the Xishan Mountains, Yunnan Province, China (lat. 24⒌ $57^{\prime} 6^{\prime \prime} \mathrm{N}$, long. $102^{\circ} 38^{\prime} 22^{\prime \prime}$ E). Plants were cultivated in plastic pots containing a humus soil obtained from the original habitat and irrigated with tap water every $5 \mathrm{~d}$; they were maintained in a greenhouse for 2 months with natural light [photosynthetic photon flux density $(P P F D) 1600 \mu \mathrm{mol} \cdot \mathrm{m}^{-2} \cdot \mathrm{s}^{-1}$ at $\left.12: 00 \mathrm{PM}\right]$ and relative humidity $\approx 50 \%$ to $60 \%$ at $25 \pm$ $5{ }^{\circ} \mathrm{C}$.

Induction of original shoots and proliferation of adventitious shoots. Tips of juvenile fronds (length, $0.8-1.2 \mathrm{~cm}$ ) used as explants (Fig. 1A) were cleaned with running tap water for $2 \mathrm{~h}$; then, they were surfacesterilized for 15 min with $0.1 \%$ (w/v) $\mathrm{HgCl}_{2}$ solution. Afterward, they were rinsed five times with sterile distilled water. Finally, surface-sterilized frond tips were inoculated on 1/2 MS media (Murashige and Skoog, $1962)$ that contained cytokinin, $3 \%(\mathrm{w} / \mathrm{v})$ sucrose, and $0.7 \%(\mathrm{w} / \mathrm{v})$ plant agar and adjusted to $\mathrm{pH} 5.8$ before being autoclaved. Using plant growth regulator (PGR)-free $1 / 2$ MS medium as a control, the effects of cytokinin on original shoot induction were evaluated at different concentrations of BAP $\left(0.1,0.5\right.$, or $\left.1.0 \mathrm{mg} \cdot \mathrm{L}^{-1}\right)$ and Thidiazuron (TDZ) $\left(0.1,0.5\right.$, or $\left.1.0 \mathrm{mg} \cdot \mathrm{L}^{-1}\right)$. Cultures were maintained in the dark at $25 \pm 2{ }^{\circ} \mathrm{C}$. After 6 weeks of culture, the induction rate of the original shoots was recorded. The original shoots were the shoots derived from the apical and lateral bud primordium. The explant forming at least one original shoot was identified as successful induction.

For the proliferation of adventitious shoots, the original shoots induced on $1 / 2$ MS with $0.1 \mathrm{mg} \cdot \mathrm{L}^{-1}$ BAP were separated from explants and subsequently cultivated on $1 / 2$ MS media with various concentrations of cytokinin (described previously); then, they were maintained in a controlled environment room at $25 \pm 2{ }^{\circ} \mathrm{C}$ under light intensity of 40 $\mu \mathrm{mol} \cdot \mathrm{m}^{-2} \cdot \mathrm{s}^{-1}$ (16 h light $/ 8 \mathrm{~h}$ dark) provided by cool-white fluorescent lamps (Philips, Netherlands). After 8 weeks of culture, the number of adventitious shoots proliferated from the single original shoot was assessed.

Plantlet cultivation and acclimatization. To obtain plantlets from adventitious shoots, the single adventitious shoot (height $\geq 5.0 \mathrm{~mm}$ ) from $1 / 2$ MS supplemented with $1.0 \mathrm{mg} \cdot \mathrm{L}^{-1}$ BAP was cultivated on PGR-free media consisting of different mineral salt concentrations ( $1 / 4 \mathrm{MS}, 1 / 2$ MS, or MS) and $0.1 \%(\mathrm{w} / \mathrm{v}) \mathrm{AC}$ or no AC. Cultures were incubated in a controlled environment room (as described previously). After 10 weeks of culture, the number of plantlets proliferated from one single adventitious shoot, root length, and frond number of plantlet were recorded.

To choose the optimal substrate type for plantlet acclimatization, the rooted plantlets (height $\geq 1.0 \mathrm{~cm}$ ) were gently washed in $0.100 \%$ to $0.125 \%$ (w/v) chlorothalonil solution and planted in plastic pots (diameter, 10 $\mathrm{cm}$ ) containing different substrate types [i.e.,
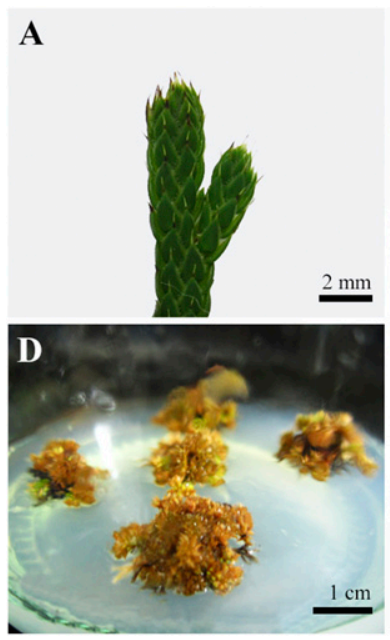

B
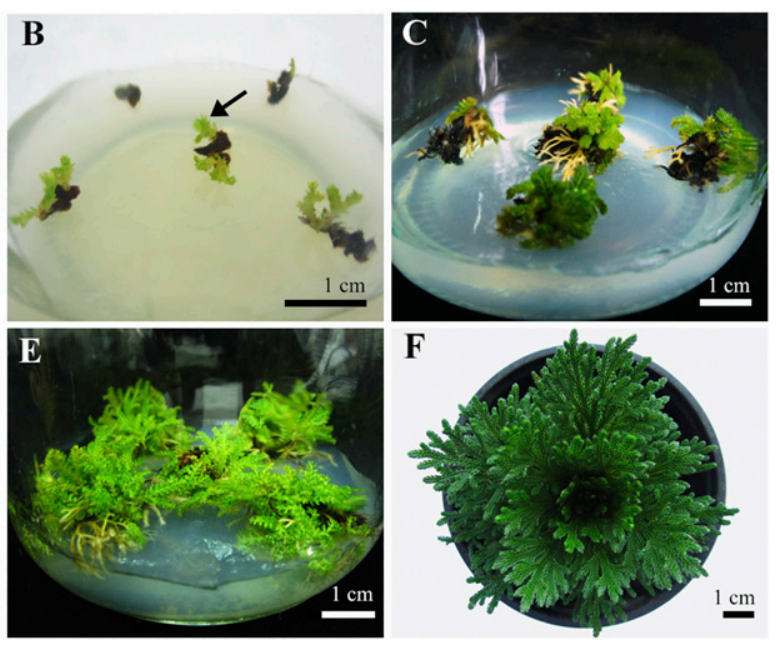

Fig. 1. In vitro propagation of resurrection plant Selaginella pulvinata. (A) Frond tip. (B) The induction of original shoots on half-strength (1/2) MS medium supplemented with $0.1 \mathrm{mg} \cdot \mathrm{L}^{-1} \mathrm{~N}^{6}$-benzylaminopurine (BAP) after 6 weeks of dark culture. The arrow indicates the original shoot. (C) The proliferation of adventitious shoots on $1 / 2 \mathrm{MS}$ medium supplemented with $1.0 \mathrm{mg} \cdot \mathrm{L}^{-1}$ BAP after 8 weeks of culture. (D) Abnormal color of the plantlets cultivated on 1/2 MS medium supplemented with $0.1 \mathrm{mg} \cdot \mathrm{L}^{-1}$ Thidiazuron (TDZ) after 8 weeks of culture. (E) Plantlets cultivated on quarter-strength (1/4) MS medium containing $0.1 \%$ (w/v) active charcoal (AC) after 10 weeks of culture. (F) The acclimated plants after 8 months of culture in the unshaded greenhouse. peat and a mixture of peat and perlite at $5: 1$ and $8: 1(\mathrm{v} / \mathrm{v})]$. All substrate type treatments included two groups: one group had 2.0 $\mathrm{kg} / \mathrm{m}^{3}$ granular slow-release fertilizer (nitrogen, $14 \%$; phosphorus, 14\%; potassium, $14 \%$; w $/ \mathrm{w}$ ) added and the other group did not. These plantlets were maintained in the shaded greenhouse $\left(P P F D, 170 \mu \mathrm{mol} \cdot \mathrm{m}^{-2} \cdot \mathrm{s}^{-1}\right.$ at 12:00 PM) at $20 \pm 5^{\circ} \mathrm{C}$. Spray irrigation was performed every 7 to $9 \mathrm{~d}$ for 4 weeks. Afterward, the shadecloth of the greenhouse was removed, and the PPFD was $\approx 1600$ $\mu \mathrm{mol} \cdot \mathrm{m}^{-2} \cdot \mathrm{s}^{-1}$ at $12: 00 \mathrm{PM}$. Plantlets were irrigated with tap water every 5 to $6 \mathrm{~d}$. The survival rate of plantlet acclimatization was recorded after 4 weeks of culture in the unshaded greenhouse.

Resurrection assessment of acclimated plants. Hydrated plants cultivated in the unshaded greenhouse for 8 months were used to assess the resurrection ability in a controlled environment room (as described previously). Hydrated plants were not irrigated for more than $10 \mathrm{~d}$ to ensure complete dehydration. The dehydrated plants were sequentially kept dry for 1 week and then rehydrated for $24 \mathrm{~h}$. The resurrection rate was recorded by the number of plants recovering to normal growth divided by the total number of plants. At the same time, the relative water content (RWC) of hydrated, dehydrated, and rehydrated plants were measured according to the records of Rapparini et al. (2015).

The chlorophyll fluorescence parameters of hydrated, dehydrated, and rehydrated plants were tested by Chlorophyll Fluorescence Imager (Technologica Inc., Essex, UK). The maximum photosystem II (PSII) efficiency at open centers $(F \mathrm{~V} / F \mathrm{~m})$ was collected after 30 min of dark adaption. Nonphotochemical fluorescence quenching (NPQ) and maximum PSII efficiency at open centers under illumination $\left(F_{\mathrm{V}^{\prime}} F_{\mathrm{m}}{ }^{\prime}\right)$ were collected after $5 \mathrm{~min}$ of light adaption under actinic light (PPFD $600 \mu \mathrm{mol} \cdot \mathrm{m}^{-2} \cdot \mathrm{s}^{-1}$ ).

Statistical analysis. Experiments were performed in a completely randomized design and repeated three times. Plantlet acclimatization experiments were conducted with three replicates, with each containing 50 plantlets. Other experiments were conducted with six replicates, with each containing five individuals. Data were analyzed by means of an analysis of variance, and the mean comparison was performed using the least significant difference and SPSS 16.0 for Windows (SPSS Inc., Chicago, IL). Significance was set at the 0.05 level.

\section{Results and Discussion}

Effects of cytokinin on the original shoot induction and adventitious shoot proliferation. Cytokinin is often used for GGB induction in fern plants (Amaki and Higuchi, 1991; Higuchi and Amaki, 1989; Yu et al., 2017b) and adventitious shoot induction in other seed plants (Alawaadh et al., 2020). Although $S$. pulvinata belongs to fern allies, GGBs were not induced by cultivating the sterilized frond tips on the media containing various 
concentrations of BAP or TDZ. Therefore, in vitro propagation via GGB should be a unique propagation system in fern species (Higuchi et al., 1987), but not in S. pulvinata. However, the adventitious shoots of $S$. pulvinata were obtained through original shoots in our study.

We tested the effects of cytokinin on the original shoot induction and adventitious shoot proliferation using PGR-free 1/2 MS medium as a control. After 6 weeks, explants in all treatments turned brown, and the original shoots derived from the apical and lateral bud primordium (Fig. 1B) occurred in all cytokinin treatments except the control. Table 1 indicates that the original shoot induction was highly dependent on the presence of cytokinin, and that the maximum of induction rate $(61.77 \pm$ $5.17 \%$ ) was obtained on $1 / 2$ MS medium containing $0.1 \mathrm{mg} \cdot \mathrm{L}^{-1} \mathrm{BAP}$.

In contrast to sunflower (Helianthus annuus) (Zhang and Finer, 2015) and coral tree (Erythrina variegate) (Javed et al., 2019), the adventitious shoots of $S$. pulvinata were not directly induced from explants; instead, they proliferated from the original shoots separated from explants and subsequently cultured on 1/2 MS media containing cytokinin. The most efficient proliferation of adventitious shoots was observed on 1/2 MS medium containing $1.0 \mathrm{mg} \cdot \mathrm{L}^{-1}$ BAP (Table 1, Fig. 1C); on average, $8.33 \pm 0.83$ adventitious shoots were proliferated from each original shoot. TDZ is an efficient cytokinin for GGB proliferation in fern plant Cibotium barometz and adventitious shoot induction in seed plants, such as Erythrina variegate (Javed et al., 2019), Fraxinus nigra (Lee and Pijut, 2017), and Scutellaria bornmuelleri (Gharari et al., 2019). Nevertheless, the addition of TDZ, especially high concentrations ( 0.5 and $\left.1.0 \mathrm{mg} \cdot \mathrm{L}^{-1}\right)$, easily resulted in the abnormal color of adventitious shoots in $S$. pulvinata (Fig. 1E), which was consistent with general expectations that TDZ could be related to morphological, physiological, and cytogenetic abnormalities in vitro (Dewir et al., 2018).

Effects of mineral salt concentration and $A C$ on plantlet growth. To obtain plantlets, single adventitious shoots were cultivated on PGR-free media. The effects of the mineral salt concentration and $\mathrm{AC}$ on plantlet growth were investigated (Table 2). Although all media were without PGR, several plantlets proliferated from one single adventitious shoot in all treatments after 10 weeks of culture (Fig. 1C). Similarly, for Punica granatum, a PGR-free medium containing 300 $\mathrm{mg} \cdot \mathrm{L}^{-1} \mathrm{AC}$ was found to effectively promote shoot multiplication during cultivation of microshoots from previous proliferation medium supplemented with $9.0 \mu \mathrm{M}$ BAP (Verma et al., 2020). This phenomenon might be related to the residual cytokinin BAP in the single adventitious shoots of $S$. pulvinata or microshoots of Punica granatum from the previous proliferation cultivation.

The mineral salt concentration and AC are associated with plantlet regeneration (Teng, 1997; da Silva et al., 2020). For example, 1/2 MS was optimal for normal sporophyte development from somatic embryos in Cyathea delgadii (Mikuła et al., 2015b), but MS favored sporophyte development in Dryopteris affinis ssp. affinis (Fernández et al., 1996). The $1 / 4$ MS medium with $0.1 \%$ or $0.2 \%$ AC promoted the plantlets regenerated from GGBs in Cibotium barometz (Yu et al., 2017b). Our results also confirmed that the low mineral salt concentration and addition of $\mathrm{AC}$ were beneficial for plantlet formation in S. pulvinata, and that the largest number of plantlets $(11.80 \pm 1.28)$ was obtained from single adventitious shoots cultivated on $1 / 4$ MS medium supplemented with $0.1 \%(\mathrm{w} / \mathrm{v})$ AC (Table 2). However, the mineral salt concentration and $\mathrm{AC}$ had no statistically significant effect on the frond number of plantlets of $S$. pulvinata (Table 2).

Moreover, a low mineral salt concentration and addition of $\mathrm{AC}$ were beneficial to the root growth of $S$. pulvinata, and the roots of plantlets cultivated on $1 / 4 \mathrm{MS}$ medium with $0.1 \%(\mathrm{w} / \mathrm{v}) \mathrm{AC}(1.66 \pm 0.11 \mathrm{~cm})$ were significantly longer than those of other treatments (Table 2). Similarly, the addition of $0.1 \%(\mathrm{w} / \mathrm{v})$ AC improved the root number and length of Magnolia 'Ann' (Parris et al., 2012), and 1/4 MS medium with $1.0 \%(\mathrm{w} / \mathrm{v})$ $\mathrm{AC}$ was the recorded optimum for the root development of fern plant Matteuccia struthiopteris (Thakur et al., 1998). In contrast, MS without $\mathrm{AC}$ was the most efficient for root development of plantlets in nonresurrection species Selaginella martensii (Park et al., 2020).

Plantlet acclimatization. The survival rate of plantlet acclimatization for all treatments was above $78 \%$ (Table 3 ). Surviving plants showed a normal phenotype (Fig. 1F). The addition of slow-release fertilizer had no significant effect on the survival rate (Table 3). In particular, the plantlets in plastic pots containing a $5: 1(\mathrm{v} / \mathrm{v})$ mixture of peat and perlite achieved the maximum survival rate $(92.13 \pm 1.67 \%)$ (Table 3$)$; therefore, it was considered the optimal substrate type for plantlet acclimatization. The same type of substrate was also suitable for the plantlet acclimatization of Cibotium barometz (Yu et al., 2017b). Nevertheless, a 3:1 mixture of horticultural substrate and decomposed granite favored the growth of acclimated plantlets in Selaginella martensii (Park et al., 2020).

Resurrection capacity of acclimated plants. In resurrection species, such as $\mathrm{Se}$ laginella lepidophylla and Boea hygrometrica, stem or leaf curling is a morphological mechanism limiting photoinhibitory and thermal damage that the plant might experience in arid environments (Rafsanjani et al., 2015; Xiao et al., 2015). In the study, all the acclimated plants used for testing (Fig. 2A) were tightly curled to form a rough sphere after dehydration (Fig. 2B) and recovered to the normal morphology after $24 \mathrm{~h}$ of rehydration (Fig. 2C). The resurrection rate was $100 \%$.

The RWC and chlorophyll fluorescence of acclimated plants in S. pulvinata significantly changed with the water conditions (Figs. 3 and 4). When dehydrated plants (RWC $6.86 \pm$ $1.04 \%$ ) (Fig. 4) were rehydrated for $24 \mathrm{~h}$, the RWC increased to $88.72 \pm 1.98 \%$ (Fig. 4), which was closer to the RWC of hydrated plants $(94.20 \pm 0.70 \%)$ (Fig. 4). At the same time, compared with the hydrated plants, the $F \mathrm{~V} / F \mathrm{~m}, \mathrm{NPQ}$, and $F_{\mathrm{V}^{\prime}} / F \mathrm{~m}^{\prime}$ of dehydrated plants sharply decreased to $0.25 \pm 0.01,0.22$ \pm 0.02 , and $0.24 \pm 0.00$, respectively. Then, these chlorophyll fluorescence parameters recovered significantly after $24 \mathrm{~h}$ of rehydration (Fig. 4). The changes in chlorophyll fluorescence parameters indicated that photosynthesis was inhibited under dehydration and revived under rehydration. A similar tendency of RWC and $F \mathrm{~V} / F \mathrm{~m}$ was also observed in resurrection plants Selaginella bryopteris (Pandey et al., 2010), Selaginella tamariscina (Xu et al., 2018), Haberlea rhodopensis (Rapparini et al., 2015), and Boea hygrometrica (Xiao et al., 2015).

Considering the resurrection rate and variable tendency of morphology, RWC, and photosynthesis, the acclimated plants of $S$. pulvinata maintained an excellent resurrection capacity. Therefore, the acclimated plants of S. pulvinata would be appropriate for studying the desiccation tolerance of resurrection plants.

Table 1. Effects of cytokinin on the original shoot induction and adventitious shoot proliferation in Selaginella pulvinata.

\begin{tabular}{|c|c|c|}
\hline$\overline{\text { Cytokinin }\left(\mathrm{mg} \cdot \mathrm{L}^{-1}\right)}$ & Original shoot induction rate $(\%)^{\mathrm{z}}$ & No. of proliferated adventitious shoots per original shoot \\
\hline$\overline{0}$ & 0.00 & - \\
\hline $0.1 \mathrm{BA}$ & $61.77 \pm 5.17 \mathrm{a}$ & $2.77 \pm 0.40 \mathrm{bc}$ \\
\hline $0.5 \mathrm{BA}$ & $24.17 \pm 3.57 \mathrm{bc}$ & $3.22 \pm 0.93 \mathrm{bc}$ \\
\hline $1.0 \mathrm{BA}$ & $8.50 \pm 3.84 \mathrm{c}$ & $8.33 \pm 0.83 \mathrm{a}$ \\
\hline $0.1 \mathrm{TDZ}$ & $34.00 \pm 7.48 b$ & $4.08 \pm 0.92 b$ \\
\hline $0.5 \mathrm{TDZ}$ & $24.00 \pm 7.48 \mathrm{bc}$ & $3.73 \pm 0.55 b$ \\
\hline 1.0 TDZ & $22.67 \pm 4.40 \mathrm{bc}$ & $1.63 \pm 0.26 \mathrm{c}$ \\
\hline
\end{tabular}

${ }^{\mathrm{z}}$ Original shoot induction rate $=$ (number of explants forming original shoot $/$ total number of explants $) \times 100 \%$.

Data are illustrated with mean \pm SE $(n=6)$. Values followed by the same lowercase letter in each column indicate that the means do not differ significantly according to the least significant difference test at the $5 \%$ level. 
Table 2. Effects of mineral salt concentration and activated charcoal (AC) on plantlet growth in Selaginella pulvinata.

\begin{tabular}{lcccc}
\hline Mineral salt concn & AC $(\%, w / v)$ & No. of proliferated plantlets per adventitious shoot & Root length $(\mathrm{cm})$ & Frond no. per plantlet \\
\hline $1 / 4 \mathrm{MS}$ & 0 & $4.80 \pm 0.58 \mathrm{bc}$ & $1.34 \pm 0.09 \mathrm{ab}$ & $5.40 \pm 0.75 \mathrm{a}$ \\
$1 / 4 \mathrm{MS}$ & 0.1 & $11.80 \pm 1.28 \mathrm{a}$ & $1.66 \pm 0.11 \mathrm{a}$ & $1.10 \pm 0.04 \mathrm{~b}$ \\
$1 / 2 \mathrm{MS}$ & 0 & $6.60 \pm 0.40 \mathrm{~b}$ & $1.06 \pm 0.09 \mathrm{bc}$ & $5.80 \pm 0.73 \mathrm{a}$ \\
$1 / 2 \mathrm{MS}$ & 0.1 & $6.20 \pm 1.53 \mathrm{~b}$ & $6.20 \pm 0.37 \mathrm{a}$ \\
MS & 0 & $4.20 \pm 0.58 \mathrm{bc}$ & $1.00 \pm 0.05 \mathrm{bc}$ & $5.80 \pm 0.37 \mathrm{a}$ \\
MS & 0.1 & $2.20 \pm 0.37 \mathrm{c}$ & $0.76 \pm 0.22 \mathrm{c}$ & $5.00 \pm 0.45 \mathrm{a}$ \\
\hline
\end{tabular}

Data are illustrated with mean \pm SE $(n=6)$. Values followed by the same lowercase letter in each column indicate that the means do not differ significantly according to least significant difference test at the $5 \%$ level.

Table 3. Effects of the substrate type and slow-release fertilizer on the survival rate of plantlet acclimatization in Selaginella pulvinata.

\begin{tabular}{lcc}
\hline Planting substrate $(\mathrm{v} / \mathrm{v})$ & Slow-release fertilizer $\left(\mathrm{kg} / \mathrm{m}^{3}\right)$ & Survival rate of plantlet acclimatization $(\%)^{\mathrm{z}}$ \\
\hline Peat & 0 & $81.94 \pm 0.12 \mathrm{bc}$ \\
Peat & 2 & $79.17 \pm 2.12 \mathrm{c}$ \\
Peat/perlite $(5: 1)$ & 0 & $92.13 \pm 1.67 \mathrm{a}$ \\
Peat/perlite $(5: 1)$ & 2 & $85.19 \pm 2.58 \mathrm{~b}$ \\
Peat/perlite $(8: 1)$ & 0 & $85.19 \pm 1.23 \mathrm{~b}$ \\
Peat/perlite (8:1) & 2 & $78.87 \pm 0.93 \mathrm{c}$ \\
\hline
\end{tabular}

${ }^{\mathrm{z}}$ Survival rate of plantlet acclimatization $=$ (number of survival plantlets / total number of plantlets for acclimatization $) \times 100 \%$.

Data are illustrated with mean \pm SE $(n=3)$. Values followed by the same lowercase letter in each column indicate that the means do not differ significantly according to least significant difference test at the $5 \%$ level.
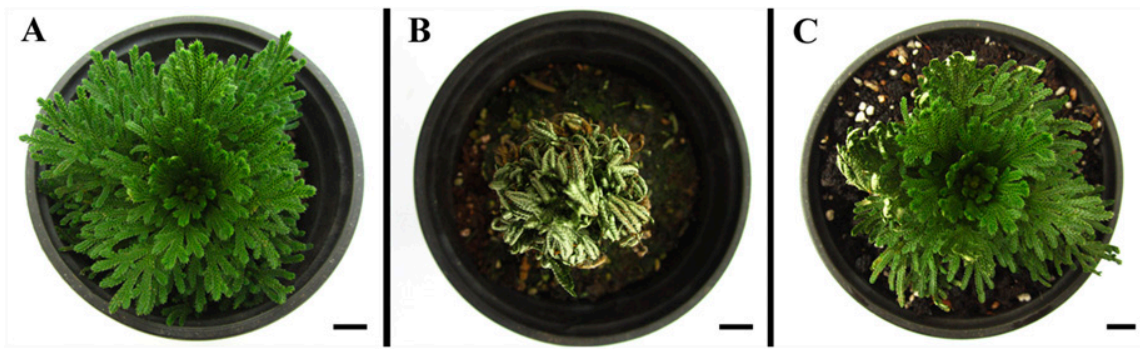

Fig. 2. The resurrection ability of the acclimated plants in Selaginella pulvinata. (A) Hydrated plant. (B) Dehydrated plant. (C) Rehydrated plant. Bar $=1 \mathrm{~cm}$
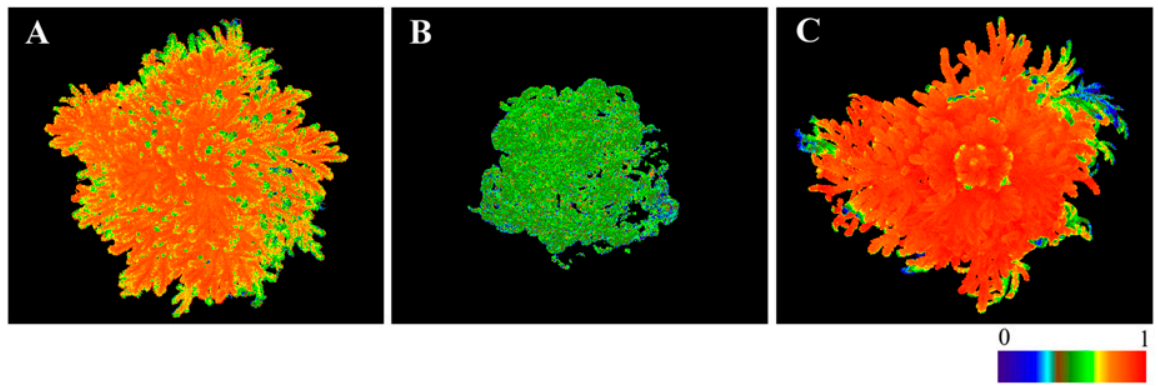

Fig. 3. Changes in chlorophyll fluorescence imaging of the maximum photosystem II (PSII) efficiency at open centers $(F \mathrm{~V} / F \mathrm{~m})$ during dehydration and rehydration of acclimated plants in Selaginella pulvinata. (A) Hydrated plant. (B) Dehydrated plant. (C) Rehydrated plant.

\section{Conclusion}

In the present study, we established an efficient in vitro propagation protocol for $S$. pulvinata using frond tips as explants. Original shoots were efficiently induced on $1 / 2$ MS medium with $0.1 \mathrm{mg} \cdot \mathrm{L}^{-1}$ BAP by using frond tips. Approximately 8.33 adventitious shoots were proliferated from one original shoot on $1 / 2$ MS medium containing 1.0 $\mathrm{mg} \cdot \mathrm{L}^{-1} \mathrm{BAP}$, which is the optimal medium for adventitious shoot proliferation. Subsequently, $\approx 11.80$ plantlets were obtained from one adventitious shoot on the optimal plant growth medium 1/4 MS supplemented with
$0.1 \%(\mathrm{w} / \mathrm{v})$ AC. Therefore, $\approx 98$ plantlets could be proliferated from one single original shoot within 18 weeks. The appropriate substrate type for plantlet acclimatization was a $5: 1(\mathrm{v} / \mathrm{v})$ mixture of peat and perlite, and the survival rate of plantlets was more than $92 \%$. A period of approximately 14 months was required from explants to mature plants via the in vitro propagation protocol. Moreover, the acclimated plants maintained excellent resurrection ability. This protocol described could be used to facilitate the rapid propagation of the resurrection plant S. pulvinata for horticultural and medicinal purposes. It could

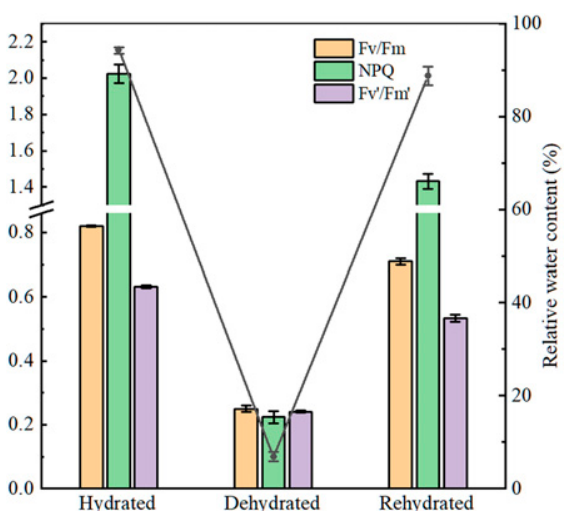

Fig. 4. Changes in the relative water content (RWC) and the chlorophyll fluorescence parameters of acclimated plants in Selaginella pulvinata during dehydration and rehydration.

also be a critical tool for researching the biology of desiccation tolerance.

\section{Literature Cited}

Alawaadh, A.A., Y.H. Dewir, M.S. Alwihibi, A.A. Aldubai, S. El-Hendawy, and Y. Naidoo. 2020. Micropropagation of lacy tree philodendron (Philodendron bipinnatifidum Schott ex Endl.). HortScience 55:294-299, doi: 10.21273/ HORTSCI14612-19.

Amaki, W. and H. Higuchi. 1991. A possible propagation system of Nephrolepis, Asplenium, Pteris, Adiantum and Rumohra (Arachniodes) through tissue culture. Acta Hort. 300:237243, doi: 10.17660/ActaHortic. 1992.300.33.

Arrigo, N., J. Therrien, C.L. Anderson, M.D Windham, C.H. Haufler, and M.S. Barker. 2013. A total evidence approach to understanding phylogenetic relationships and ecological diversity in Selaginella subg. Tetragonostachys. Amer. J. Bot. 100:1672-1682, doi: 10.3732/ajb.1200426.

Barnicoat, H., R. Cripps, J. Kendon, and V. Sarasan. 2011. Conservation in vitro of rare and threatened ferns - case studies of biodiversity hotspot and island species. Vitro Cell. Dev-Pl. 47(1):3745, doi: 10.1007/s11627-010-9303-x. 
Baniaga, A.E., N. Arrigo, and M.S. Barker. 2016. The small nuclear genomes of Selaginella are associated with a low rate of genome size evolution. Genome Biol. Evol. 8:1516-1525, doi: 10.1093/gbe/evw091.

Banks, J.A. 2009. Selaginella and 400 million years of separation. Annu. Rev. Plant Biol. 60:223-238, doi: 10.1146/annurev.arplant.59.032607.092851.

Camloha, M., N. Gogala, and J. Rode. 1994. Plant regeneration from leaf explants of the fern Platycerium bifurcatum in vitro. Scientia Hort. 56:257266, doi: 10.1016/0304-4238(94)90007-8.

Cao, Y., J.J. Chen, N.H. Tan, L. Oberer, T. Wagner, Y.P. Wu, G.Z. Zeng, H. Yan, and Q. Wang. 2010. Antimicrobial selaginellin derivatives from Selaginella pulvinata. Bioorg. Med. Chem. Lett. 20:2456-2460, doi: 10.1016/j.bmcl.2010.03.016.

Chinese Pharmacopoeia Committee. 2015, Pharmacopoeia of the People's Republic of China. China Medical Science and Technology Press, Beijing.

da Silva, D.P.C., P.D. de Oliveira Paiva, R.C Herrera, J.M.P. Porto, M.V. dos Reis, and R. Paiva. 2020. Effectiveness of silicon sources for in vitro development of gerbera. Plant Cell Tissue Organ Cult. 141:77-85, doi: 10.1007/ s11240-020-01768-8.

Deeba, F., A.K. Pandey, and V. Pandey. 2016. Organ specific proteomic dissection of Selaginella bryopteris undergoing dehydration and rehydration. Front. Plant Sci. 7:425, doi: 10.3389/ fpls.2016.00425.

Dewir, Y.H., Y. Naidoo, and J.A.T. da Silva. 2018 Thidiazuron-induced abnormalities in plant tissue cultures. Plant Cell Rep. 37:1451-1470, doi: 10.1007/s00299-018-2326-1.

Fernández, H., A.M. Bertrand, and R. SáchezTamés. 1996. Micropropagation and phase change in Blechnum spicant and Pteris ensiformis. Plant Cell Tissue Organ Cult. 44:261265, doi: 10.1007/BF00048534.

Gharari, Z., K. Bagheri, A. Sharafi, and H. Danafar. 2019. Thidiazuron induced efficient in vitro organogenesis and regeneration of Scutellaria bornmuelleri: An important medicinal plant. In Vitro Cell. Dev. Biol. Plant 55:133-138, doi: 10.1007/s11627-019-09965-7.

Hegde, S., V.K. Menon, R. Noronha, and L. D'Souza. 2006. Callus culture and an unconventional pattern of sporophyte regeneration in Drynaria quercifolia - a medicinal fern. In Vitro Cell. Dev. Biol. Plant 42:508-513, doi: 10.1079/IVP2006810.

Higuchi, H., W. Amaki, and S. Suzuki. 1987. In vitro propagation of Nephrolepis cordifolia Prsel. Scientia Hort. 32:105-113, doi: 10.1016/03044238(87)90021-5.

Higuchi, H. and W. Amaki. 1989. Effects of 6benzylaminopurine on the organogenesis of Asplenium nidus L. through in vitro propagation. Scientia Hort. 37:351-359, doi: 10.1016 0304-4238(89)90146-5.

Huang, Y., X. Liu, D. Wu, G. Tang, Z. Lai, X. Zheng, Y. Sheng, and H.B. Luo. 2017. The discovery, complex crystal structure, and recognition mechanism of a novel natural PDE4 inhibitor from Selaginella pulvinata. Biochem. Pharmacol. 130:51-59, doi: 10.1016/ j.bcp.2017.01.016.

Javed, S.B., A.A. Alatar, M. Anis, and M.A. ElSheikh. 2019. In vitro regeneration of coral tree from three different explants using thidiazuron. HortTechnology 29:946-951, doi: 10.21273/ HORTTECH04398-19.

Jermy, A.C. 1986. Subgeneric names in Selaginella. Fern Gaz. 13:117-118.
Lee, J.H. and P.M. Pijut. 2017. Adventitious shoot regeneration from in vitro leaf explants of Fraxinus nigra. Plant Cell Tissue Organ Cult. 130:335-343, doi: 10.1007/s11240-017-1228-1. Little, D.P., R.C. Moran, E.D. Brenner, and D.W. Stevenson. 2007. Nuclear genome size in $\mathrm{Se}$ laginella. Genome 50:351-356, doi: 10.1139/ G06-138.

Mikuła, A., M. Pożoga, K. Tomiczak, and J. Rybczyński. 2015a. Somatic embryogenesis in ferns: A new experimental system. Plant Cell Rep. 34:783-794, doi: 10.1007/s00299015-1741-9.

Mikuła, A., M. Pożoga, M. Grzyb, and J. Rybczyński. 2015b. An unique system of somatic embryogenesis in the tree fern Cyathea delgadii Sternb.: The importance of explant type, and physical and chemical factors. Plant Cell Tissue Organ Cult. 123:467-478, doi: 10.1007/s11240-015-0850-z.

Murashige, T. and F. Skoog. 1962. A revised medium for rapid growth and bioassays with tobacco tissue cultures. Physiol. Plant. 15:473497.

Obermayer, R., I.J. Leitch, L. Hanson, and M.D. Bennett. 2002. Nuclear DNA C-values in 30 species double the familial representation in pteridophytes. Ann. Bot. 90:209-217, doi: 10.1093/aob/mcf167.

Pampurova, S., K. Verschooten, N. Avonce, and P. Van Dijck. 2014. Functional screening of a cDNA library from the desiccation-tolerant plant Selaginella lepidophylla in yeast mutants identifies trehalose biosynthesis genes of plant and microbial origin. J. Plant Res. 127:803813, doi: 10.1007/s10265-014-0663-x.

Pandey, V., S. Ranjan, F. Deeba, A.K. Pandey, R. Singh, P.A. Shirke, and U.V. Pathre. 2010. Desiccation-induced physiological and biochemical changes in resurrection plant, Selaginella bryopteris. J. Plant Physiol. 167:1351-1359, doi: 10.1016/j.jplph.2010.05.001.

Park, K., B.K. Jang, H.M. Lee, J.S. Cho, and C.H. Lee. 2020. An efficient method for in vitro shoot-tip culture and sporophyte production using Selaginella martensii Spring sporophyte. Plants 9:235, doi: 10.3390/plants9020235.

Parris, J.K., D.H. Touchell, T.G. Ranney, and J. Adelberg. 2012. Basal salt composition, cytokinins, and phenolic binding agents influence in vitro growth and ex vitro establishment of Magnolia 'Ann'. HortScience 47:1625-1629, doi: 10.21273/HORTSCI.47.11.1625.

Rafsanjani, A., V. Brule, T.L. Western, and D. Pasini. 2015. Hydroresponsive curling of the resurrection plant Selaginella lepidophylla. Sci. Rep. 5:8064, doi: 10.1038/srep08064.

Rapparini, F., L. Neri, G. Mihailova, S. Petkova, and K. Georgieva. 2015. Growth irradiance affects the photoprotective mechanisms of the resurrection angiosperm Haberlea rhodopensis Friv. in response to desiccation and rehydration at morphological, physiological and biochemical levels. Environ. Exp. Bot. 113:67-79, doi: 10.1016/j.envexpbot.2015.01.007.

Singh, S.K., S.K. Shukla, N.K. Dubey, P.K. Shukla, and R.V. Lansdown. 2019. Morphological studies of the ligules of selected Indian species of Selaginella (Selaginellaceae). Flora 252:69 75, doi: 10.1016/j.flora.2019.02.009.

Teng, W.L. 1997. Activated charcoal affects morphogenesis and enhances sporophyte regeneration during leaf cell suspension culture of Platycerium bifurcatum. Plant Cell Rep. 17:77-83, doi: $10.1007 / \mathrm{s} 002990050356$.

Thakur, R.C., Y. Hosoi, and K. Ishii. 1998. Rapid in vitro propagation of Matteuccia struthiopte- ris (L.) Todaro - an edible fern. Plant Cell Rep. 18:203-208, doi: 10.1007/s002990050557.

VanBuren, R., C.M. Wai, S. Ou, J. Pardo, D. Bryant, N. Jiang, T.C. Mockler, P. Edger, and T.P. Michael. 2018. Extreme haplotype variation in the desiccation-tolerant clubmoss $\mathrm{Se}$ laginella lepidophylla. Nat. Commun. 9:13, doi: 10.1038/s41467-017-02546-5.

Verma, V., G. Zinta, and K. Kanwar. 2020. Optimization of efficient direct organogenesis protocol for Punica granatum L. cv. Kandhari Kabuli from mature leaf explants. In Vitro Cell. \& Dev -Pl. 1-12. doi: 10.1007/s11627-02010111-x.

Wang, X., S. Chen, H. Zhang, L. Shi, F. Cao, L. Guo, Y. Xie, T. Wang, X. Yan, and S. Dai. 2010. Desiccation tolerance mechanism in resurrection fern-ally Selaginella tamariscina revealed by physiological and proteomic analysis. J. Proteome Res. 9:6561-6577, doi: 10.1021/pr100767k.

Wang, Y.D., J.Z. Zhang, Y.H. Wang, J. Yang, H.Y. $\mathrm{Li}$, and L.M. Cai. 2016. Anti-proliferative constituents from Selaginella pulvinata. Phytochem. Lett. 15:26-29, doi: 10.1016/j.phytol.2015.10.021.

Winarto, B. and J.A. Teixeira da Silva. 2012. Improved micropropagation protocol for leatherleaf fern (Rumohra adiantiformis) using rhizomes as donor explant. Scientia Hort. 140:74-80, doi: 10.1016/j.scienta.2012.03.017.

Xiao, L., G. Yang, L. Zhang, X. Yang, S. Zhao, Z. Ji, Q. Zhou, M. Hu, Y. Wang, and M. Chen. 2015. The resurrection genome of Boea hygrometrica: A blueprint for survival of dehydration. Acad. Sci. USA 112:5833-5837, doi: 10.1073/pnas. 1505811112 .

Xu, Z., T. Xin, D. Bartels, Y. Li, W. Gu, H. Yao, S. Liu, H. Yu, X. Pu, J. Zhou, J. Xu, C. Xi, H. Lei, J. Song, and S. Chen. 2018. Genome analysis of the ancient tracheophyte Selaginella tamariscina reveals evolutionary features relevant to the acquisition of desiccation tolerance. Mol. Plant 11:983-994, doi: 10.1016/j.molp.2018.05.003.

Yobi, A., B.W. Wone, W. Xu, D.C. Alexander, L. Guo, J.A. Ryals, M.J. Oliver, and J.C. Cushman. 2013. Metabolomic profiling in Selaginella lepidophylla at various hydration states provides new insights into the mechanistic basis of desiccation tolerance. Mol. Plant 6:369-385, doi: 10.1093/mp/sss155.

$\mathrm{Yu}$, R., A.E. Baniaga, S.A. Jorgensen, and M.S. Barker. 2017a. A successful in vitro propagation technique for resurrection plants of the Selaginellaceae. Amer. Fern J. 107:96-105, doi: 10.1640/0002-8444-107.2.96.

Yu, R., G. Zhang, H. Li, H. Cao, X. Mo, M. Gui, X. Zhou, Y. Jiang, S. Li, and J. Wang. 2017b. In vitro propagation of the endangered tree fern Cibotium barometz through formation of green globular bodies. Plant Cell Tissue Organ Cult. 128:369-379, doi: 10.1007/s11240-016-1116-0.

Zhang, Z. and J.J. Finer. 2015. Sunflower (Helianthus annuus L.) organogenesis from primary leaves of young seedlings preconditioned by cytokinin. Plant Cell Tissue Organ Cult. 123:645-655, doi: 10.1007/ s11240-015-0867-3.

Zhang, L.B. and X.C. Zhang. 2004. Flora of China 6(3). Science Press, Beijing.

Zhou, X.M., C.J. Rothfels, L. Zhang, Z.R. He, T. Le Péchon, H. He, N.T. Lu, R. Knapp, D. Lorence, and X.J. He. 2016. A large-scale phylogeny of the lycophyte genus Selaginella (Selaginellaceae: Lycopodiopsida) based on plastid and nuclear loci. Cladistics 32:360389, doi: 10.1111/cla.12136. 